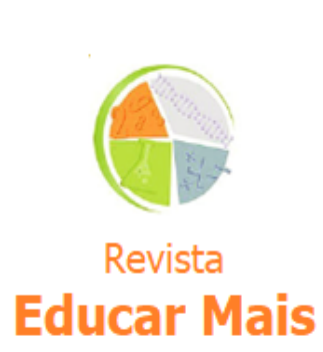

\title{
EDITORIAL
}

\section{Percursos profissionais de cientistas e professores de ciências}

\author{
Prof. Dr. Paulo Lima Junior ${ }^{1}$
}

Não há dúvida de que a educação em ciências está atravessando uma crise (FOUREZ, 2003). Enquanto as crianças dos anos iniciais do ensino fundamental são tipicamente descritas como criativas e motivadas, a relação que passam a desenvolver com a ciência escolar ao entrar no ensino médio tende ao desinteresse (TYTLER et al., 2008). De fato, estudantes de diversas regiões do mundo experimentam uma queda no interesse por ciência ao longo da educação secundária (POTVIN; HASNI, 2014). Com alguma razão, muitos estudantes consideram a ciência escolar demasiadamente abstrata e desconectada da vida real (KRAPP; PRENZEL, 2011), restando poucos motivos para seguir carreira em C\&T. Em outras regiões, os alunos até reconhecem a relevância da ciência, mas não se identificam com ela: "ciência é importante, mas não é para mim" (JENKINS; NELSON, 2005). De qualquer maneira, observamos que muitos jovens talentosos e promissores estão interrompendo precocemente seus percursos científicos. Mas por que isso deve ser considerado motivo para falar em crise?

Em alguns dos países onde o ensino médio está organizado em torno de itinerários formativos distintos, a busca por percursos que envolvam tópicos avançados de ciência diminuiu substancialmente ao longo das últimas décadas (LYONS, 2006; OSBORNE; SIMON; COLLINS, 2003). Nesses países, quando um estudante opta por um itinerário formativo sem ciências da natureza, muitas oportunidades são canceladas. Não estou falando aqui somente da oportunidade de seguir carreiras científicas em sentido estrito (física, química, biologia), mas de todas as engenharias (civil, mecânica, elétrica, computacional, ambiental), profissões da saúde (enfermagem, nutrição, farmácia, medicina, veterinária) e profissões do mercado (economia, contabilidade, estatística). Todos os percursos profissionais que dependem dos conhecimentos em ciências da natureza e matemática são impactados quando a educação científica escolar falha em desenvolver competências e despertar o interesse dos estudantes. Por essas e muitas outras razões, o declínio do interesse científico dos jovens tem sido considerado um desafio para a manutenção do estado de bem-estar social (ANDERHAG et al., 2016).

Ao mesmo tempo em que o desempenho em ciências da natureza dos estudantes brasileiros está entre os piores do mundo (LIMA JUNIOR; FRAGA JUNIOR, 2021), nossa economia se desindustrializa (OREIRO; FEIJÓ, 2010) e o movimento anticiência se fortalece. Entre os desdobramentos concretos

\footnotetext{
${ }^{1}$ Possui Graduação em Física, Mestrado e Doutorado em Ensino de Física e Pós-Doutorado em Didática das Ciências Naturais pela Universidade de Estocolmo, Suécia. Professor Adjunto da Universidade de Brasília e membro permanente do Programa de Pós-Graduação em Educação em Ciências da Universidade de Brasília (UnB), Brasília/DF - Brasil. E-mail: paulolimajr@unb.br
} 
desse movimento, encontramos diversas ações contrárias ao espírito democrático (OLIVEIRA, 2021; TOLLEFSON, 2019): a demissão de cientistas competentes, a desqualificação das instituições científicas, o estrangulamento dos investimentos e a prática da censura. Tudo isso é feito sob a aparência de discordâncias que até poderiam ser discutidas seriamente (sobre o aquecimento global, as queimadas na Amazônia, a efetividade do isolamento social, do uso de máscaras ou das vacinas). Porém, o propósito real dessas manobras retóricas é desconstruir a credibilidade da ciência, favorecendo a defesa de posições econômicas, políticas e religiosas completamente arbitrárias (ARTAXO, 2019).

Em última análise, a crise da ciência brasileira remonta à relação que os cidadãos estabelecem com o conhecimento científico. Segundo a pesquisa sobre a imagem pública da ciência no Brasil (CGEE, 2017), ainda que os brasileiros defendam mais recursos para ciência, a imagem do cientista sofreu um desgaste progressivo entre os anos 2010 e 2019. Esses dados permitem perceber que a crise em que a ciência brasileira se encontra hoje não surgiu do dia para a noite, mas foi construída ao longo de muitos anos. Em síntese, essa crise só é possível em uma sociedade que pouco conhece e pouco se interessa pela ciência.

É verdade que o desinteresse e a desmotivação dos estudantes representam um incômodo recorrente para grande parte dos professores. Porém, a literatura recente tem sublinhado que interesses e motivações não são meramente individuais ou intrínsecos (CLAUSSEN; OSBORNE, 2013). Eles não dizem respeito somente à satisfação imediata que um estudante pode sentir ao realizar uma atividade científica. Respostas afetivas ("eu amo isso!"), juízos de valor ("que ideia importante!") e aspirações profissionais ("quero trabalhar com isso!") estão inscritas em projetos e estilos de vida mais ou menos específicos. Quando nós situamos os interesses dos alunos em seus projetos de vida, percebemos que estar interessado ciências implica os estudantes em certas lutas sociais.

Para a maioria dos estudantes, a escolha por permanecer estudando ciências após a educação compulsória está relacionada à posição social da família (ANDERHAG et al., 2013) e, mais especificamente, à congruência entre as formas de capital disponíveis nas famílias e as expectativas que os cursos de ciências são capazes de produzir (LYONS, 2006). Portanto, estar interessado em ciências é uma questão de classe na medida em que a posse de certas formas de capital favorece ou dificulta o interesse científico dos estudantes. A saber, a percepção de que o interesse dos estudantes é uma questão de classe tem incentivado diversas iniciativas de educação científica das periferias urbanas (GARCIA-SILVA; LIMA JUNIOR, 2020).

Uma análise rápida do perfil dos profissionais das áreas de C\&T mostrará que eles são tipicamente homens heterossexuais (BRITO; PAVANI; LIMA JUNIOR, 2015). Por isso, faz sentido dizer que os percursos científicos estão implicados em questões de gênero. Essa desigualdade estrutural repercute de diversas maneiras sobre as mulheres que optam por carreiras científicas, gerando, para elas, obstáculos singulares (MARTINS; LIMA JUNIOR, 2020). Em resposta a essa situação, a literatura está repleta de propostas que pretendem incluir a agenda feminista da escola e na formação de professores (HEERDT; BATISTA, 2016) seja por inspiração das epistemologias feministas (GEDOZ; PEREIRA DE PEREIRA; BORGES PAVANI, 2020; HARDING, 1986) ou pelas análises pós-modernas das feminilidades e masculinidades científicas (ARCHER et al., 2012; CARLONE et al., 2015; DANIELSSON; LUNDIN, 2014; ROSA, 2018).

A preocupação com o interesse por carreiras científicas entre os jovens desdobra-se em outros temas importantes, tais como a evasão dos cursos de graduação (GILIOLI, 2016; SILVA FILHO et al., 2007) 
e o abandono ou permanência da carreira docente (RUIZ; RAMOS; HINGEL, 2007). Guardadas as particularidades de cada tema, o desenvolvimento do interesse pela ciência, a escolha de uma carreira na área de C\&T e a permanência no curso são acontecimentos que fazem mais sentido quando inscritos na história de vida de indivíduos socialmente configurados que lutam em vista de certos propósitos.

De fato, quando um jovem opta por carreiras relacionadas à ciência, outras barreiras ainda precisam ser ultrapassadas. As altas taxas de evasão dos cursos de graduação mostram que muitos jovens talentosos abandonam sua formação sem concluí-la (GILIOLI, 2016; SILVA FILHO et al., 2007). Descontados alguns casos de contratendência (MASSI; VILLANI, 2015), cursos de ciências exatas geralmente apresentam as taxas de evasão mais elevadas de suas instituições. De maneira geral, a conclusão da graduação depende da origem social do estudante (KNOP; COLLARES, 2019) ainda que essa relação seja atenuada tanto nas universidades públicas quanto nos cursos de menor apelo comercial. Porém, mesmo nos contextos em que não há relação evidente entre evasão e origem social (LIMA JUNIOR; OSTERMANN; REZENDE, 2012, 2013a), questões de classe são impactantes para os percursos formativos dos estudantes (FERNANDES et al., 2020; HEIDEMANN; ESPINOSA, 2020; MARTINS; LIMA JUNIOR, 2020).

Ainda que as taxas de evasão do curso de Física sejam elevadas para todos os segmentos que dele participam, a integração social e acadêmica dos estudantes das periferias urbanas parece ser prejudicada (LIMA JUNIOR et al., 2020a). Além disso, tendo em vista as incertezas da profissão científica, a pressão por excelência nos cursos de Física pode dificultar a integração social e acadêmica dos graduandos (LIMA JUNIOR et al., 2020b). Quando falamos dos cursos de licenciatura, outras particularidades precisam ser lembradas. Afinal, para aqueles que escolherem trabalhar como professores de ciências, algumas lutas sociais comuns a todos os professores tendem a surgir. Designamos por proletarização (CONTRERAS, 2002) a perda de controle do processo de trabalho pelos professores. A suspeição dos professores pelo movimento "escola sem partido" ao lado da militarização das escolas púbicas são, talvez, os adventos mais recentes desse processo. Portanto, resistir à proletarização é uma luta na qual todos os professores de ciências costumam estar implicados desde o momento de sua escolha profissional (LIMA JUNIOR, 2018).

Por todas essas razões, as histórias de vida individuais podem ser consideradas uma arena na qual se travam todas as lutas sociais: o enfrentamento da proletarização da docência, do conservadorismo, do patriarcado, do racismo, do elitismo e muitas outras. Todas essas lutas são travadas diariamente na vida das pessoas concretas em seus percursos acadêmicos e profissionais pela ciência. Escolher e permanecer um curso ou profissão científica implica assumir uma série de desafios que são, ao mesmo tempo, singulares e plurais.

Adotar as histórias de vida como objeto de análise tendo em vista o enfrentamento das desigualdades sociais supõe evitar duas posições extremas (BOURDIEU, 1990): o objetivismo, segundo o qual as ações individuais são completamente determinadas pelas estruturas sociais; e o subjetivismo, segundo o qual as ações individuais podem ser compreendidas a despeito das estruturas sociais.

Objetivistas geralmente resistem a pensar os atores individuais como personagens responsáveis, capazes de escrever suas próprias histórias. Para eles, todas as formas de autonomia são ilusórias. Movimentos de resistência e luta são empreendimentos obrigatoriamente coletivos. Os personagens da História são a classe, o movimento social organizado, o sindicato, as instituições, o Estado. Os indivíduos relevantes são heróis da revolução, grandes capitalistas, estadistas, cientistas. As lutas 
diárias empreendidas por pessoas comuns não merecem a mesma atenção dispensada aos grandes heróis, posto que não ajudariam a entender como os processos macrossociais se desdobram. As análises das histórias individuais são geralmente desprezadas sob o pretexto de resistência ao fetichismo individualista. Nisso, os objetivistas acertam na análise, mas erram na ação. De fato, o estágio atual do desenvolvimento capitalista, por razões bem conhecidas, tem produzido uma intensificação dos processos de individualização (BECK, 1992). Em consequência, as pessoas são menos propensas a se identificar com sua classe, sua profissão, suas famílias, seus pares. Multiplicamse os negros contrários ao enfrentamento do racismo, os homossexuais contrários ao movimento LGBT, as mulheres antifeministas... Esse é um fenômeno que não pode ser negligenciado e resulta justamente do fato de que desigualdades sociais tendem a ser invisíveis à escala individual. Nesses casos, estamos mesmo falando de uma autonomia ilusória: a mulher conservadora e antifeminista não está menos sujeita às violências que atingem as demais mulheres, por mais que acredite estar (e tanto pior para ela será acreditar assim!). Mas disso não decorre que todas as experiências de autonomia individual sejam ilusórias. Tampouco decorre dai que todas as análises biográficas e autobiográficas sejam subjetivistas.

Os subjetivistas, por sua vez, são mais difíceis de detalhar, pois são um grupo muito heterogêneo e disperso. Uma vez que a modernidade tardia multiplicou as maneiras de celebrar a fantasia da ação individual sem estrutura social (BECK, 1992), há muitas formas diferentes de ser subjetivista. A meritocracia (BOURDIEU, 2007; NOGUEIRA; NOGUEIRA, 2009), por exemplo, é uma ideologia subjetivista muito popular entre os conservadores: acreditam que seu sucesso na escola, na profissão, nos negócios resulta somente de seus esforços, sem perceber a medida em que seu sucesso é socialmente configurado. Por óbvio, a posição dos meritocratas é tão mais confortável quanto menos nós formos capazes de explicitar os mecanismos propriamente simbólicos do privilégio escolar (LIMA JUNIOR; PINHEIRO; OSTERMANN, 2012). Já no campo da psicologia da aprendizagem, o cognitivismo pode ser considerado o principal representante do pensamento subjetivista na medida em que minimiza o caráter sociocultural da mente individual (DE PEREIRA; LIMA JUNIOR, 2014; LIMA JUNIOR; OSTERMANN; REZENDE, 2013b). O silenciamento que o cognitivismo individualista opera com respeito às desigualdades sociais é, sem dúvida, conveniente para os pesquisadores que sustentam posições políticas mais conservadoras.

Quando politicamente mobilizados em torno de pautas progressistas, os subjetivistas podem apresentar alguma dificuldade com a ideia de que todos os sujeitos são necessariamente assujeitados (BUTLER, 2004). As normas, instituições e estruturas sociais contra as quais nós frequentemente nos opomos (família, escola, ciência, política, misoginia, racismo, homofobia...) não estão fora de nós, mas são o ponto de partida da nossa existência. Em outras palavras, aquele que enfrenta as estruturas sociais só é capaz de fazê-lo por estar configurado em todos os seus detalhes pelas mesmas estruturas contra as quais luta. O leitor atento à natureza social da constituição individual observará que muitas afirmações acadêmicas de caráter progressista são, na verdade, revestidas de um romantismo quixotesco. Acadêmicos subjetivistas de esquerda, movidos por uma leitura seletiva ou equivocada dos autores da pós-modernidade, da decolonialidade, da pesquisa narrativa, geralmente elegem a ciência ou o campo acadêmico como inimigo sem perceber que dele fazem parte o tempo todo. A principal revolução que conhecem é a escrita subjetiva, que permitiria expressar mais livremente seus sentimentos, fortalecendo a ilusão de que são mais autênticos, quando, na verdade, participam de um movimento bem estabelecido no campo educacional. 
Em oposição a essas duas maneiras de pensar os percursos profissionais reportados pela pesquisa biográfica ou autobiográfica, vários pesquisadores têm buscando inspiração na teoria performática do gênero (BUTLER, 2004), na contracontação de estórias da teoria crítica da raça (SOLÓRZANO; YOSSO, 2002) ou nos chamados retratos sociológicos (LAHIRE, 2004) desenvolvidos a partir de uma apropriação crítica da teoria da prática de Bourdieu (LAHIRE, 2002). Essa última metodologia foi discutida em nossa área (LIMA JUNIOR; MASSI, 2015) e posteriormente empregada para analisar os percursos formativos de professores de ciências (MASSI; LIMA JUNIOR; BAROLI, 2018). Ela certamente é um caminho promissor para investigarmos o desenvolvimento do interesse pela ciência ou pela docência, bem como a escolha e permanência nos cursos e nas profissões relacionadas á ciência.

\section{REFERÊNCIAS}

ANDERHAG, P. et al. Students' choice of post-compulsory science: in search of schools that compensate for the socio-economic background of their students. International Journal of Science Education, [s. I.], v. 35, n. 18, p. 3141-3160, 2013. Available at: https://doi.org/10.1080/09500693.2012.696738

ANDERHAG, P. et al. Why do secondary school students lose their interest in science? Or does it never emerge? A possible and overlooked explanation. Science Education, [s. l.], v. 100, n. 5, p. 791-813, 2016. Available at: https://doi.org/10.1002/sce.21231

ARCHER, L. et al. "Balancing acts": elementary school girls' negotiations of femininity, achievement, and science. Science Education, [s. l.], v. 96, n. 6, p. 967-989, 2012. Available at: https://doi.org/10.1002/sce.21031

ARTAXO, P. A quem interessa atacar a ciência? E por quê? Jornal da USP, São Paulo, 2019. BECK, U. Risk society: towards a new modernity. London: Sage Publications, 1992.

BOURDIEU, P. A distinção: critica social do julgamento. Porto Alegre: ZOUK, 2007. BOURDIEU, P. The logic of practice. Stanford: Stanford University Press, 1990.

BRITO, C.; PAVANI, D.; LIMA JUNIOR, P. Meninas na ciência: atraindo jovens mulheres para carreiras de ciência e tecnologia. Gênero, [s. l.], v. 16, n. 1, p. 33-50, 2015.

BUTLER, J. Undoing gender. London: Routledge, 2004.

CARLONE, H. B. et al. What kind of boy does science? A critical perspective on the science trajectories of four scientifically talented boys. Science Education, [s. l.], v. 99, n. 3, p. 438-464, 2015. Available at: https://doi.org/10.1002/sce.21155

CGEE. A ciência e a tecnologia no olhar dos brasileiros: Percepção pública da C\&T no Brasil - 2015. Brasília: [s. n.], 2017.

CLAUSSEN, S.; OSBORNE, J. Bourdieu's notion of cultural capital and its implications for the science curriculum. Science Education, [s. I.], v. 97, n. 1, p. 58-79, 2013. Available at:

https://doi.org/10.1002/sce.21040

CONTRERAS, J. Autonomia de professores. São Paulo: Cortez, 2002. 
DANIELSSON, A. T.; LUNDIN, M. Gender performativity in physics: Affordances or only constraints? Cultural Studies of Science Education, [s. I.], v. 9, n. 2, p. 523-529, 2014. Available at: https://doi.org/10.1007/s11422-012-9420-4

DE PEREIRA, A. P.; LIMA JUNIOR, P. Implicações da perspectiva de Wertsch para a interpretação da teoria de Vygotsky no ensino de Física. Caderno Brasileiro de Ensino de Física, [s. l.], v. 31, n. 3, p. 518-535, 2014. Available at: https://doi.org/http://dx.doi.org/10.5007/2175$7941.2014 \mathrm{v} 31 \mathrm{n} 3 \mathrm{p} 518$

FERNANDES, J. et al. Estudo da evasão dos estudantes de licenciatura e bacharelado em física: uma análise à luz da teoria do sistema de ensino de Bourdieu. Caderno Brasileiro de Ensino de Física, [s. l.], v. 37, n. 1, p. 105-126, 2020. Available at: https://doi.org/10.5007/21757941.2020v37n1p105

FOUREZ, G. Crise no ensino de ciências? Investigações em Ensino de Ciências, [s. l.], v. 8, n. 2, p. 109-123, 2003.

GARCIA-SILVA, S.; LIMA JUNIOR, P. A educação científica das periferias urbanas: uma revisão sobre o ensino de ciências em contextos de vulnerabilidade social (1985-2018). Revista Brasileira de Pesquisa em Educação em Ciências, [s. l.], p. 221-243, 2020. Available at: https://doi.org/10.28976/1984-2686rbpec2020u221243

GEDOZ, L.; PEREIRA DE PEREIRA, A.; BORGES PAVANI, D. Maneiras de conhecer e implicações para a equidade de gênero na educação em ciências. Revista Brasileira de Pesquisa em Educação em Ciências, [s. I.], p. 775-798, 2020. Available at: https://doi.org/10.28976/19842686rbpec2020u775798

GILIOLI, R. de S. P. Evasão em instituições federais de ensino superior no brasil: expansão da rede, SiSU e desafios. [S. I.], p. 55, 2016.

HARDING, S. The science question in feminism. Ithaca: Cornell University Press, 1986.

HEERDT, B.; BATISTA, I. D. L. Questões de gênero e da natureza da ciência na formação docente. Investigações em Ensino de Ciências, [s. l.], v. 21, n. 2, p. 30, 2016. Available at: https://doi.org/10.22600/1518-8795.ienci2016v21n2p30

HEIDEMANN, L. A.; ESPINOSA, T. A evasão nos cursos de graduação: como entender o problema? Revista Educar Mais, [s. l.], v. 4, n. 3, p. 451-459, 2020. Available at: https://doi.org/10.15536/reducarmais.4.2020.1939

JENKINS, E. W.; NELSON, N. W. Important but not for me: students' attitudes towards secondary school science in England. Research in Science \& Technological Education, [s. I.], v. 23, n. 1, p. 41-57, 2005. Available at: https://doi.org/10.1080/02635140500068435

KNOP, M.; COLLARES, A. C. M. A influência da origem social na probabilidade de concluir os diferentes cursos de ensino superior. Sociedade e Estado, [s. I.], v. 34, n. 2, p. 351-380, 2019. Available at: https://doi.org/10.1590/s0102-6992-201934020001

KRAPP, A.; PRENZEL, M. Research on interest in science: Theories, methods, and findings. International Journal of Science Education, [s. l.], v. 33, n. 1, p. 27-50, 2011. Available at: https://doi.org/10.1080/09500693.2010.518645

LAHIRE, B. Reprodução ou prolongamentos críticos? Educação \& Sociedade, [s. l.], v. 23, n. 78, p. 37-55, 2002. Available at: https://doi.org/10.1590/S0101-73302002000200004 
LAHIRE. Retratos sociológicos: disposições e variações individuais. Porto Alegre: Artmed, 2004.

LIMA JUNIOR, P. et al. A integração dos estudantes de periferia no curso de Física: razões institucionais da evasão segundo a origem social. Ciência \& Educação, [s. l.], v. 26, 2020a.

LIMA JUNIOR, P. et al. Excelência, evasão e experiências de integração dos estudantes de graduação em Física. Ensaio Pesquisa em Educação em Ciências (Belo Horizonte), [s. l.], v. 22, p. 1-23, 2020b. Available at: https://doi.org/10.1590/21172020210140

LIMA JUNIOR, P. Trajetórias dos professores de ciências em tempos de proletarização: família e vocação docente. In: MASSI, L.; LIMA JUNIOR, P.; BAROLLI, E. (org.). Retratos da docência: contextos, saberes e trajetórias. Araraquara: Letraria, 2018. p. 435-459.

LIMA JUNIOR, P.; FRAGA JUNIOR, J. C. Qual é o efeito da desigualdade social no desempenho em ciências dos estudantes brasileiros? Uma análise do Exame Nacional do Ensino Médio (2012-2019). Investigações em Ensino de Ciências -, [s. l.], v. 26, n. 1, p. no prelo, 2021.

LIMA JUNIOR, P.; MASSI, L. Retratos sociológicos: uma metodologia de investigação para a pesquisa em educação. Ciência \& Educacão, [s. l.], v. 21, n. 3, p. 559-574, 2015.

LIMA JUNIOR, P.; OSTERMANN, F.; REZENDE, F. Análise dos condicionantes sociais da evasão e retenção em cursos de graduação em física à luz da sociologia de Bourdieu. Revista Brasileira de Pesquisa em Educação em Ciências, [s. l.], v. 12, n. 1, p. 37-60, 2012.

LIMA JUNIOR, P.; OSTERMANN, F.; REZENDE, F. Análise dos condicionantes sociais do sucesso acadêmico em cursos de graduação em física à luz da sociologia de Bourdieu. Ensaio Pesquisa em Educação em Ciências, [s. l.], v. 15, n. 1, p. 113-129, 2013a.

LIMA JUNIOR, P.; OSTERMANN, F.; REZENDE, F. Marxism in Vygotskian approaches to cultural studies of science education. Cultural Studies of Science Education, [s. l.], v. 9, n. 3, p. 1-24, 2013b. Available at: https://doi.org/10.1007/s11422-013-9485-8

LIMA JUNIOR, P.; PINHEIRO, N.; OSTERMANN, F. Bourdieu en la educación científica: consecuencias para la enseñanza y la investigación. Didáctica de las Ciencias Experimentales y Sociales, [s. I.], v. 160, n. 26, p. 145-160, 2012. Available at: https://doi.org/10.7203/dces.26.1925

LYONS, T. The puzzle of falling enrolments in physics and chemistry courses: Putting some pieces together. Research in Science Education, [s. l.], v. 36, n. 3, p. 285-311, 2006. Available at: https://doi.org/10.1007/s11165-005-9008-z

MARTINS, A. M.; LIMA JUNIOR, P. Identidade e desenvolvimento profissional de professores de ciências como uma questão de gênero: o caso de Natália Flores. Investigações em Ensino de Ciências, [s. l.], v. 25, n. 3, p. 616, 2020. Available at: https://doi.org/10.22600/15188795.ienci2020v25n3p616

MASSI, L.; LIMA JUNIOR, P.; BAROLI, E. Reatratos da docência: contextos, saberes e trajetórias [Portraits of teaching: context, knowledge and trajectory]. Araraquara: Letraria, 2018. E-book.

MASSI, L.; VILLANI, A. Um caso de contratendência: baixa evasão na licenciatura em química explicada pelas disposições e integrações. Educação e Pesquisa, [s. l.], v. 41, n. 4, p. 975-992, 2015. Available at: https://doi.org/10.1590/s1517-9702201512135667 
NOGUEIRA, C. M. M.; NOGUEIRA, M. A. Bourdieu e a Educação. Belo Horizonte: Autêntica, 2009.

OLIVEIRA, E. "Se é intimidação, não vai funcionar", diz ex-reitor que foi alvo de processo por criticar Bolsonaro em reunião. G1, [S. l.], 2021.

OREIRO, J. L.; FEIJÓ, C. A. Desindustrialização: conceituação, causas, efeitos e o caso brasileiro. Revista de Economia Política, [s. I.], v. 30, n. 2, p. 219-232, 2010. Available at: https://doi.org/10.1590/S0101-31572010000200003

OSBORNE, J.; SIMON, S.; COLLINS, S. Attitudes towards science: A review of the literature and its implications. International Journal of Science Education, [s. I.], v. 25, n. 9, p. 1049-1079, 2003. Available at: https://doi.org/10.1080/0950069032000032199

POTVIN, P.; HASNI, A. Interest, motivation and attitude towards science and technology at K-12 levels: a systematic review of 12 years of educational research. Studies in Science Education, [s. l.], v. 50, n. 1, p. 85-129, 2014. Available at: https://doi.org/10.1080/03057267.2014.881626

ROSA, K. Science identity possibilities: a look into Blackness, masculinities, and economic power relations. Cultural Studies of Science Education, [s. I.], v. 13, n. 4, p. 1005-1013, 2018. Available at: https://doi.org/10.1007/s11422-018-9859-z

RUIZ, A. I.; RAMOS, M. N.; HINGEL, M. Escassez de professores no ensino médio: propostas estruturais e emergenciais. Brasília: Ministério da Educação, 2007.

SILVA FILHO, R. L. L. e et al. A evasão no ensino superior brasileiro. Cadernos de Pesquisa, [ $s$. I.], v. 37, n. 132, p. 641-659, 2007. Available at: https://doi.org/10.1590/S0100-

15742007000300007

SOLÓRZANO, D. G.; YOSSO, T. J. Critical Race Methodology: Counter-Storytelling as an Analytical Framework for Education Research. Qualitative Inquiry, [s. I.], v. 8, n. 1, p. 23-44, 2002. Available at: https://doi.org/10.1177/107780040200800103

TOLLEFSON, J. 'Tropical Trump' sparks unprecedented crisis for Brazilian science. Nature, [s. l.], v. 572, n. 7768, p. 161-162, 2019. Available at: https://doi.org/10.1038/d41586-019-02353-6

TYTLER, R. et al. Opening up pathways: engagement in STEM across the primarysecondary school transition. Canberra: [s. n.], 2008. 